\title{
Corpo-vitrine, ser mulher e saúde: produção de sentidos nas capas da Revista Boa Forma
}

\section{Showcase body type, being a woman and health: sense production on the covers of $\mathrm{Ba}$ Forramagazine}

Maria Teresa de Assis Campos ${ }^{1,2}$
Mariana Silva Cecílio
Fernanda Rodrigues de Oliveira
Penafortet,

' Universidade Federal do Triângulo Mineiro, Instituto de Educação, Letras, Artes, Ciências Humanas e Sociais, Departamento de Psicologia, Programa de Pós-graduação em Psicologia. Uberaba-MG, Brasil.

${ }^{2}$ Universidade Federal do Triângulo Mineiro, Laboratório de Estudos e Pesquisa em Sexualidade e Violência de Gênero Uberaba-MG, Brasil.

${ }^{3}$ Universidade Federal do Triângulo Mineiro, Laboratório de Investigações sobre Práticas Dialógicas e Relacionamentos Interpessoais. Uberaba-MG, Brasil.

${ }^{4}$ Universidade Federal do Triângulo Mineiro, Instituto de Ciências da Saúde, Departamento de Nutrição.Uberaba-MG, Brasil.

${ }^{5}$ Universidade de São Paulo, Faculdade de Medicina de Ribeirão Preto, Curso de Nutrição e Metabolismo, Laboratório de Práticas e Comportamento Alimentares. Ribeirão Preto-SP, Brasil.

Correspondência / Correspondence Fernanda Rodrigues de Oliveira Penaforte Departamento de Nutrição, Universidade Federal do Triângulo Mineiro (UFTM)

Av. Getúlio Guaritá, 159, sala 321. CEP: $38025-$

440. Uberaba-MG. Brasil.

Email: fernandapenaforte@yahoo.com.br

\section{Resumo}

Considerando as representações de corpo belo, jovem, magro e livre de imperfeições, corpos femininos idealizados parecem ser regidos pela ideia difundida, em campanhas publicitárias, de que quanto mais esculpidos, mais felizes e resolvidas são suas donas. Diante desse cenário, o objetivo deste estudo é compreender de que forma ocorre a produção de sentidos sobre o feminino e o corpo no discurso produzido pelas capas da revista Boa Forma. Respaldado nos campos de discussão da Nutrição e da Psicologia, o estudo pautou-se na abordagem qualitativa de pesquisa, selecionando as 12 capas (edições) impressas do ano de 2015. As capas foram submetidas a análise discursiva, primeiro elencando aspectos mais evidentes e, posteriormente, mais profundos, que originou a constituição de três corpus: Discursos corporificados: o ideal de beleza como objeto de estudo; Ser mulher, ser corpo, ser abdômen; e $O$ corpo obeso, as dietas e a saúde. Observou-se intrínseca associação entre dieta, saúde e beleza, utilizando estratégias midiáticas de conotação persuasiva sobre os cuidados necessários com o corpo. A alusão ao conceito de boa forma parece estar ao alcance de todas mulheres e ligada, exclusivamente, ao mérito delas. Foi possível também inferir que, como um exercício de controle sobre os corpos, as dietas são planejadas para não funcionarem, assim como os ideais de corpo são feitos para não serem atingidos, podendo gerar sentimentos de culpa, transtornos alimentares e tensões, refletindo nas identidades dos sujeitos. Assim, o estudo mostrou-se importante para atentarmos às "verdades" naturalizadas a que estamos sujeitos.

Palavras-chave: Corpo. Saúde. Estética. Revistas Femininas. Análise do Discurso. 


\section{Abstract}

Considering the representations of beautiful, young, thin and imperfection-free bodies, idealized female bodies seem to be governed by the widespread idea in advertising campaigns that the more sculpted a body is, the happier and more confident their owners are. In this scenario, the aim of this study is to understand how feelings are produced about women and the body in the discourse produced by the covers of Boa Forma magazine. Supported by the discussion in the fields of nutrition and psychology, this study was based on qualitative research. Twelve covers (editions) were selected, printed in the year 2015. The covers underwent discursive analysis, first by enumerating the more evident aspects, and later the more thorough aspects, which led to the creation of three corpora: Embodied speeches: the ideal of beauty as an object of study; Being a woman, being a body, being an abdomen and The obese body, diets and health. There was an intrinsic relationship between diet, health and beauty, using the media strategies of persuasive connotation about the necessary precautions with the body. The allusion in the concept of good shape seems to be available to all women and linked exclusively to their merit. It could be inferred that, as an exercise of control over women's bodies, diets are designed not to work and ideal body images are produced not to be achieved, which can generate feelings of guilt, eating disorders and tensions, with consequences to the identities of subjects. Thus, the study showed the importance of awareness of naturalized "truths" we are subjected to.

Key words: Body. Health. Beauty. Women's Magazines. Discourse Analysis.

\section{Introdução}

Considerando que as concepções de estética corporal estão intimamente imbricadas nas transformações políticas, econômicas, socioculturais e históricas, parece ser inevitável mencionar que os modos de existir e se apresentar, conforme os valores da época, são construídos socialmente e frutos de um processo. Trata-se de um processo no qual signos culturais são superestimados, para que haja constante adaptação às demandas sociais, sobretudo por meio de uma camuflagem mercadológica, fomentando uma busca insaciável por um investimento em si, para o reconhecimento do outro. ${ }^{1}$

Colocando o bem-estar em xeque, frente às exigências da sociedade quanto, por exemplo, a hábitos, posturas e padrões de comportamento a serem executados para se obter prestígio, o ideal 
de corpo acaba por incitar que homens e mulheres se sujeitem à influência não apenas sobre seu corpo, mas também sobre sua subjetividade. Especificamente sobre as mulheres, apesar de suas conquistas sociais serem destacadas quando contextualizadas em uma cultura de desigualdade de gênero que as coloca em condição de inferioridade social, ${ }^{2}$ elas permanecem como principal alvo das propagandas publicitárias. Essas propagandas tendem fazer alusão a maior liberdade e apropriação de seus próprios interesses, que incitam a ideia de que devem seguir modelos de apreciação estética, ao mesmo tempo que essa autonomia deve ser cerceada por algum mecanismo de controle. ${ }^{1,3}$ Quer dizer, além de provocar identificações com os produtos vendidos, a publicidade acaba por vender uma maneira de pensar e agir que, supostamente, se personalizaria em uma maneira de existir, de ser lembrada e, sobretudo, de ser (re)conhecida.

Dessa forma, a partir de discursos que construiriam "verdades", transmitidas pelos meios de comunicação, as mulheres, submetidas às ideias veiculadas de como melhor se expor e se relacionar com o mundo, acabam se deparando com uma dupla armadilha paradoxal: sentir-se incluídas socialmente e frustrar-se por não conseguir atingir seu objetivo, gerando uma eterna insatisfação que as leva a adotar medidas radicais que podem desencadear, por sua vez, distúrbios alimentares ou até mesmo sintomas psicopatológicos. ${ }^{1-6}$

Formatados em padrões magros e com curvas, os corpos femininos idealizados parecem ser regidos pela ideia difundida de que, quanto mais esculpidos, mais felizes e resolvidas são suas donas. Partindo desse pressuposto, arraigado no imaginário de corpo belo, jovem, leve e livre de imperfeições instigando uma imagem escultural, o objeto-corpo parece transitar em uma lógica universal que refuta a singularidade e a originalidade, normatizando e uniformizando expectativas e perspectivas utópicas e, como se não bastasse, sob a propaganda do imediatismo e da rapidez para atingir estereótipos femininos. ${ }^{2,4,7}$

Estratégias de marketing são elaboradas pela associação entre dieta, saúde e beleza, como se beleza e saúde se correspondessem mutuamente sob o mesmo imperativo: cuidado ao corpo, ${ }^{5}$ sendo que as imagens na mídia e em campanhas publicitárias de corpos de mulheres como objeto de desejo reforçam o hiperindividualismo, culminando em sentimentos de responsabilização e culpabilização por não se adequar ao que é culturalmente cultuado e valorizado. ${ }^{6,8}$ Sobre esses aspectos vale ressaltar, portanto, a conotação reguladora de prescrever, vigiar e cobrar o alcance do bem-estar tão cobiçado, sob o pano de fundo do elogio à moderação e a busca por resultados profícuos perpassados pela ilusão de acesso à beleza que estaria ao "alcance de todos". ${ }^{6}$

Como diria Goldenberg, ${ }^{9}$ falar de corpo e gênero em outros tempos seria falar de temas fúteis. No entanto, considerando os inúmeros debates que visam abarcar reflexões sobre cultura, gênero, corporeidade e influências publicitárias como fontes potenciais na constituição de uma subjetividade não somente individual mas coletiva, a literatura vem avançando em estudos que buscam compreender como tais questões reverberam em uma perspectiva micro e macrossocial, 
sobretudo na cultura brasileira. ${ }^{7,10-13}$ Diante desse cenário, o objetivo do presente estudo é compreender de que forma ocorre a produção de sentidos sobre o feminino e o corpo no discurso produzido pelas capas da revista Boa Forma. Nesse sentido, a presente discussão pretende também não apenas suscitar questionamentos acerca da maneira como as informações são transmitidas e repetidas para gerar impacto nos leitores, como comparar o discurso produzido das capas da revista sobre corpo e alimentação com aquele que é produzido na área da saúde, respaldando-se em considerações dos campos de discussão da Nutrição e da Psicologia.

\section{Método}

A realização deste estudo pautou-se na abordagem qualitativa de pesquisa, buscando fazer um recorte dos sentidos produzidos e veiculados sobre o corpo e o feminino pela revista Boa Forma. A escolha se deu por ser esta a revista feminina de cuidados com o corpo de maior circulação nacional na atualidade. Para tanto, foram selecionadas 12 capas impressas do ano de 2015, por compor um ano de produção e se tratar de uma veiculação mais recente e próxima da escrita deste artigo. O período de um ano foi priorizado como amostra, pois esse é comumente o intervalo considerado pela indústria da moda e beleza para iniciar e finalizar ciclos de tendências e normatizações sobre o que é belo, adequado e pertinente nesse universo.

Selecionada a amostra, todo material passou, primeiramente, por uma análise superficial, na qual foram elencados os aspectos mais evidentes e de maior impacto dispostos nas capas; em seguida, eles foram listados e submetidos à análise discursiva. Posteriormente, um levantamento mais aprofundado foi realizado, atentando para questões não tão evidentes numa primeira impressão. Terminadas as análises, três corpora foram constituídos: Discursos corporificados: o ideal de beleza como objeto de estudo; Ser mulher, ser corpo, ser abdômen e $O$ corpo obeso, as dietas e a saúde. Os três serão apresentados e discutidos a seguir.

\section{Resultados e Discussão}

Compreendendo a importância que o referencial teórico selecionado para a análise dos dados representa para o delineamento desta discussão, é importante fazer uma breve explanação sobre a fundamentação que o embasa e sobre a justificativa por sua escolha. Será utilizada para analisar e discutir os dados a Análise do Discurso de tradição francesa, estabelecida por Michel Pêcheux..$^{14} \mathrm{~A}$ escolha se deve, dentre muitas razões, por duas em especial: a primeira, pelo fato de que ela permite estender o olhar para toda materialidade que produza sentido - ou seja, não há necessidade da linguagem oral ou escrita para sua aplicação, podendo alcançar, por exemplo, os sentidos produzidos pela escolha da imagem que estampa a capa da revista. A segunda, por sua 
vez, refere-se à importância que a análise discursiva atribui à Ideologia que atua nos processos discursivos de produção de sentido, ressaltando as relações de poder que estão presentes em sua conjuntura e no processo de constituição humana, seja ela individual ou social..$^{15}$

Vale ressaltar que a Análise do Discurso recusa a concepção da linguagem como ferramenta neutra e ingênua de explicação e interpretação do mundo, assumindo que a mesma está projetada para que os equívocos ocorram, permitindo a atuação da Ideologia por meio de suas fendas. Dessa forma, as condições materiais da produção dos discursos são evidenciadas, demonstrando que a linguagem vai além do que é dito, situando os sujeitos que falam em relação à posição e ao contexto sócio-histórico-cultural de onde falam. ${ }^{16}$

A Ideologia é conceito indispensável à Análise do Discurso, sendo compreendida como um mecanismo inconsciente de falseamento da realidade que exerce a manutenção dos interesses das classes dominantes. Para tal, ela se utiliza de dois mecanismos principais, sendo o primeiro deles a naturalização dos modos de relação na sociedade; e o segundo, a individuação dos sujeitos atrelada à ideia de meritocracia. Ou seja, é a ilusão de que os sujeitos estão destacados entre si e são únicos responsáveis por seus sucessos e fracassos, retirando-os de seus contextos sócio-históricos e posicionando-os como seres isentos de história e imunes com relação às condições sociais que os circunscrevem. ${ }^{17}$

No que diz respeito à linguagem, há dois mecanismos essenciais que permitem a manifestação e perpetuação da Ideologia: os Esquecimentos 1 e 2. O Esquecimento número 1 pode ser definido como a ilusão de autoria que embala os sujeitos quando produzem discursos, enquanto o Esquecimento número 2 faz menção à ideia de que o discurso produzido só poderia se constituir das exatas palavras que foram utilizadas por ele. ${ }^{18}$

Por fim, compreendendo que a linguagem transcende a ideia de mera ferramenta de comunicação e é capaz de revelar os aspectos ideológicos que operam na manutenção dos discursos de poder, este estudo considerou a Análise do Discurso como instrumento adequado para a análise dos dados obtidos. Tal escolha possibilita transpassar aquilo que parece óbvio na composição das capas e alcançar os sentidos produzidos (e vendidos) sobre os corpos femininos na atualidade.

Tendo em vista a concepção de linguagem, discurso e Ideologia apresentadas pela Análise do Discurso, os dados levantados a partir das capas possibilitaram a constituição de três corpora analíticos que serão trabalhados detalhadamente nesta discussão.

\section{Discursos corporificados: o ideal de beleza como objeto de estudo}

O que a publicidade diz, de que forma ela diz, será que ela se contradiz? Questionamentos como esses ganham visibilidade quando a discussão remete ao dilema travado entre o lado 
publicitário da propaganda e o lado do desejo insaciável de pessoas motivadas a assegurar o produto ofertado, carregado de expectativas e fantasias do quão promissora será a vida a partir dessa ilusória garantia. ${ }^{1}$ Garantia de boa f(ô)rma, de bem-estar, de estar dentro dos padrões de beleza em destaque na sociedade, de felicidade pela conquista de caráter essencialmente meritocrático ${ }^{17}$ e de conseguir, em uma luta constante contra o tempo, atingir seus objetivos de maneira rápida.

Conforme mencionado, a análise deste artigo recai sobre as 12 capas da revista Boa Forma do ano de 2015. De imediato, é inevitável comentar os discursos incididos a partir do jogo de imagens, palavras e fontes utilizadas como recursos midiáticos de impacto da mensagem a ser não apenas transmitida, mas vinculada a filiações de sentidos evocados a partir de memórias e circunstâncias, em imbricada interlocução entre os contextos imediatos e sócio-históricos, deixando vestígios de apreensão para a Análise do Discurso (AD) que permite atravessar o imaginário em que as discursividades são (re)produzidas. ${ }^{18}$

Em todas as capas, é possível pressupor que o corpo ideal exibido pelas modelos - sempre sorridentes e sensuais - se fecha nas possibilidades de um corpo magro, moldado a suaves curvas e trabalhado esculturalmente em academia. Observa-se também preocupação com a estética dos corpos em relação ao vestuário da moda utilizada, associada com frequência tanto à mensagem veiculada quanto ao plano de fundo que visa chamar atenção para espaços verdes, fitness e de praia, combinando tonalidades. Nesse sentido, corpos definidos devem ficar à mostra, com o mínimo de roupa possível, tendo em vista que o corpo seria a verdadeira roupa, defendendo a ideia de uma mulher descolada, cheia de vida, independente e resolvida. Quer dizer, configurado como um espaço simbólico na construção dos modos de subjetividade e identidade, ligado aos estados de ânimo, o corpo passa a ser possível alvo de dominação e controle, ao prescrever normas de conduta e valores, uma forma de capital (físico, econômico, simbólico e social), sendo sua exaltação e supervalorização aproveitadas como mecanismos., ${ }^{712}$

Como para a AD todo material que produza sentido é passível de análise, ${ }^{18}$ aprofundando-se em detalhes podemos notar não somente o tipo corporal a ser difundido, mas o que transcende a linguagem e os sentidos produzidos pela imagem, a partir do modo como determinadas palavras e expressões aparecem em alto relevo, instigando seu público, essencialmente feminino, a atentar para: (a) partes do corpo - abdômen, barriga, cintura, cabelo, pele, pernas, bumbum; (b) alimentação - detox, cardápio funcional, receitas fáceis e rápidas, dietas, alimentos que derretem gordura, redução e restrição de alimentos, dicas para comer melhor; (c) exercícios e condicionamento físico - "treino de apenas quatro exercícios", série power, circuito acelerado; (d) a promessa de resultados a serem conquistados com garantia - congelamento de gordura, liquidação do peso extra, "queima por 48h", diminuição de inchaço e aceleramento do metabolismo, equilíbrio de hormônios, tonificação e definição do tônus muscular, realização de desejos; e (e) a promessa de tempo a curto prazo - "em um mês", estratégias e truques express, "em um pulo", "em cinco minutos", dieta flex, "resultados rápidos". Como podemos supor, tendo em vista que manuais e 
revistas prometeriam regimes e estratégias infalíveis, o cuidar do corpo parece ter adquirido aos poucos um caráter de necessidade, muito a partir de um poder persuasivo da indústria do corpo que estimula a preocupação com alimentação, produtos de beleza, atividades físicas e até mesmo outros recursos médicos de intervenção estética. ${ }^{7,19}$

Especificamente sobre o último aspecto destacado, cabe ressaltar que as capas apresentam informações supracitadas acerca da agilidade para se atingir o corpo magro, denotado como ideal, ou chegar o mais próximo, queimando calorias no menor tempo possível. Mas, pensando na rotina das mulheres tanto no domínio público quanto privado, será que elas possuem de fato tempo ${ }^{20}$ para responderem às demandas sociais às quais estão e são sujeitas a todo instante, e também a reservarem um momento hábil para esculpir e manter um corpo-vitrine? Duas edições ressaltam que a agenda apertada das modelos (Gisele Bündchen e Sabrina Sato) não são um empecilho para não malhar mesmo sem tempo. Sobre esse ponto, como salienta, ${ }^{7}$ revistas especializadas levam o público leitor a acreditar que não seguir as orientações de experts configuraria uma negligência pessoal, visto que com disciplina e força de vontade qualquer um conseguiria ao menos chegar próximo à aparência do padrão de beleza vigente e conquistar a sonhada satisfação de maneira imediata, resgatando o conceito de meritocracia pela ideia de que as mesmas condições estariam disponíveis para todos..$^{17,21}$

Partindo dessa discussão, apresenta-se como relevante salientar a utilização de verbos que convidam não somente à ideia de faça e conquiste, como também o que você deveria fazer, os desafios que devem ser superados ou até mesmo a ideia de pode tudo, mas com restrições. Nesse sentido, encontramos a utilização de metáforas e eufemismos para substituir termos de impacto por outros mais agradáveis e suaves, como: "Alimentos para sumir com a pochete", "acabe com o peso extra", ou ainda, "aparelhos que derretem a gordurinha". " Como propuseram Vilhena et al. ${ }^{21}$ sobre a publicidade televisiva, a linguagem deve ser a mais simples possível, intercalando notícias boas e ruins - como na revista é plausível dizer das chamadas de promessas garantidas, bem como do dever de executar o que está sendo proposto para esse alcance, poupando o leitor do trabalho de pensar a partir de uma apropriação crítica e seletiva do discurso veiculado.

Deve-se destacar que as chamadas da revista não se restringem ao convite da conquista e alcance da boa forma, mas parecem estimular avidez, pela dedicação à conquista do corpo ideal/magro/ perfeito, visto que sempre será possível melhorar e aperfeiçoar. ${ }^{7}$ Assim, nota-se uma estratégia de instigar a leitora a sentir deleite na execução das atividades propostas: "Apaixone-se pela corrida: a gente ensina", bo intuito de promover a ideia de um encontro consigo mesma e com as sensações prazerosas ao cuidar do seu corpo, disfarçando a ideia de mal necessário. ${ }^{19}$

\footnotetext{
a Estes trechos foram retirados, respectivamente, das revistas Boa Forma dos meses de agosto, abril e agosto de 2015.

b Esses trechos foram retirados da revista Boa Forma do mês de fevereiro de 2015 .
} 
Mas será que essas sugestões são acessíveis a todas as mulheres e a todos os corpos femininos? Sendo o centro das atenções, o destaque da publicidade parece camuflar os paradoxos e conflitos entre enaltecer a singularidade e, ao mesmo tempo, negar a alteridade e diferença, dissimulando particularidades sociais, históricas, contextuais e, inclusive, orgânicas. Fomenta-se, assim, a ilusão ideológica de que todas as mulheres nascem com as mesmas ferramentas e, portanto, têm as mesmas condições para a busca do corpo defendido como ideal ${ }^{7}$, o que explica a ideia de Siqueira \& Faria $^{22}$ sobre "produção de subjetividade capitalística", em que o foco é o universal, a comunicação em massa. Esse aspecto pode nos levar a sugerir a ideia de coerção e controle sociais que levam à conformação do corpo a um padrão estético exigente. ${ }^{19}$ Assim, em todos esses casos, o que se observa é um falseamento da realidade, bem como de práticas inclusivas em que a mulher teria que se "espremer" para caber em um meio discursivo-social, entendendo-se tratar da representação de um corpo feminino perfeito ${ }^{23}$ e resgatando experiências passadas presentificadas em uma nova roupagem de palavras. ${ }^{18}$

Deve-se também acrescentar que, dentre todas as capas, apenas uma apresentou o anúncio "Alerta de Saúde"b que, supostamente, levaria a leitora a questionar quais os possíveis riscos à saúde em detrimento ao cuidado com a beleza, sugerindo não ser uma preocupação recorrente da revista. Além disso, outra proposta se refere aos passos para se alcançar a felicidade com o corpo desejado, permitindo-nos fazer alusão à responsabilidade e à hiperindividualização ${ }^{6,8}$ pela garantia de bem-estar físico, emocional e nutricional, o que pode desencadear sentimentos de frustração, impotência e culpa caso não consiga seguir à risca comandos tão "fáceis". Como recurso estratégico, é importante mencionar que a revista faz algumas chamadas para afinar a relação entre bem-estar físico e bem-estar mental, como "saiba por que um sorriso vale por um tratamento de beleza" ou "é coisa da sua cabeça", talvez sob o subentendido conceito de wellness, mencionado por Siqueira e Faria. ${ }^{22}$ Assim, parece ficar evidente a ideia de um padrão de beleza inalcançável, bem como sujeito a adoecimentos frente a demanda da leitura do emagrecer, ser bonita e saudável, desconsiderando que o corpo magro depende de outros domínios de cuidado, não se restringindo a dietas e exercícios físicos, e confundindo certificação de inclusão social e condições do corpo. ${ }^{7}$

Diante dessa contextualização, vale mencionar que as modelos utilizadas para veicular a mensagem representam, majoritariamente, o corpo branco e mulheres de status com o mesmo estereótipo estético enxuto, produzindo o ar de perfeição. ${ }^{12}$ A revista parece se aproveitar da concepção já difundida sócio-culturalmente de que a relação com o mundo, sobretudo quando falamos da ponte do domínio privado com o público, envolve a mediação da corporeidade - ou seja, o corpo em uma relação dialética com o social. ${ }^{7}$ Além disso, aproveita-se do fato de a cultura brasileira transformar o corpo natural em capital..$^{12}$

c Estes trechos foram retirados, respectivamente, das revistas Boa Forma dos meses de maio e dezembro de 2015. 


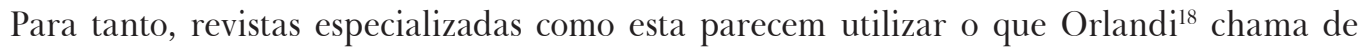
Mecanismo de antecipação, na tentativa tanto de experimentar o que o leitor "ouve", como de antecipar o sentido produzido pelo leitor quando este acessa a informação com o intuito de regular o efeito a ser nele produzido. Mostra-se interessante, portanto, pensarmos para que tipo de mulher é endereçado esse tipo de revista, considerando a ideia de que nenhum discurso é meramente ingênuo, sem um propósito ou neutro, e que o não dito fala por si, sendo também um recurso de comunicação em que os sentidos estão constantemente sendo "administrados". ${ }^{18}$

Pelo perfil jovem das modelos, é possível a reflexão de que mulheres casadas e com filhos não sejam o foco da revista. Apesar da chamada que, em uma única edição, instiga a inclusão do marido na dieta e as estratégias para não engordar depois do casamento, observa-se certa invisibilidade tanto à imagem de uma modelo que represente essas mulheres quanto a um discurso que não se subtraia em adquirir uma beleza jovem. ${ }^{12}$ Percebe-se o esforço de algumas edições sobre a possibilidade de se atingir um corpo perfeito após a gestação, ou após determinada idade, mas também impera a interpretação de que, na verdade, é reforçado o sentimento de culpa recaído culturalmente sobre essas mulheres.

Nesse ínterim, traduzido em um corpo mais fino e elegante, fica evidente como a aparência é especulada tanto como porta de entrada para o (re)conhecimento do outro, quanto como um prérequisito para se conquistar um pretendente. ${ }^{3}$ Apresentando a mulher como "mais contemporânea que a contemporaneidade", tipo ideal, a imprensa parece ocupar papel educador/formador, lançando mão de um forte dispositivo de poder: a comunicação mercadológica, ${ }^{22}$ que exploraremos melhor no corpus a seguir.

\section{Ser mulher, ser corpo, ser abdômen}

Desde muito cedo, a partir do momento em que se é concebido enquanto ser humano, diversos discursos de poder e normatização envolvem os sujeitos, afetando direta ou indiretamente seus corpos, identidades e subjetividades. Esses discursos traçam e determinam o que é ou não adequado para cada um, ditando como devem se dar os comportamentos, afetos e, inclusive, a estética dos corpos. ${ }^{24}$ Esses discursos são reproduzidos pelas instituições/atividades corriqueiras das rotinas dos sujeitos, bem como a Ideologia também se utiliza desses mecanismos, como, por exemplo, revistas de cuidado com o corpo, como a utilizada por este estudo. ${ }^{25}$

É possível notar, assim, que a revista não promove apenas um padrão de corpo a ser adotado, mas também carrega consigo uma ideia e concepção do feminino. Observando a capa, é possível notar de imediato o perfil das modelos estampadas: magras, enquadradas perfeitamente aos padrões do que é considerado bonito na cultura contemporânea, cabelos perfeitamente alinhados, ausência de qualquer marca na pele, alternando expressões de felicidade e sensualidade, brancas 
(apesar de haver um aparente esforço em representar as várias possibilidades estéticas do Brasil, apenas uma modelo negra ocupa lugar em uma das capas ao longo de um ano, havendo um padrão étnico recorrente nas publicações), famosas e bem-sucedidas. É importante salientar que as modelos escolhidas normalmente estão em posição de destaque no mês do lançamento da revista, como, por exemplo, em papéis de protagonistas em alguma novela que está obtendo altos índices de audiência.

Nota-se que é apresentada pela revista uma mulher modelo, na qual as outras mulheres podem/ devem se espelhar, uma mulher que consegue abarcar todas as demandas que perpassam sua existência com primor, ou seja, mulheres que ocupam a classe alta, trabalham em empregos de prestígio e conseguem junto a isso tudo se manterem bonitas e magras. Ao longo da apresentação dessas mulheres, é possível perceber uma descontextualização tanto das modelos quanto do públicoalvo da revista. Cria-se a ilusão de que todas as mulheres são, ou podem ser, como as apresentadas pela capa, tendo suas particularidades descartadas e passando por um processo de esvaziamento histórico-contextual, ferramenta ideológica importante que possibilita o falseamento que ocorre quando se acredita que todos os sujeitos encontram-se na mesma posição histórico-social. ${ }^{17}$

É possível perceber outras estratégias utilizadas para criar a ilusão de proximidade entre as leitoras e as modelos da capa, como, por exemplo, o uso da palavra "segredo", aplicado sempre em relação nominal com a modelo - "Camila Queiroz, os segredos de beleza da atriz do ano" ou em "Tainá Muller, os segredos que mantém o corpo da atriz magro (e o cabelo lindo)". ${ }^{\mathrm{d}}$ Ao grafar a palavra "segredo", cria-se a ilusão de intimidade entre a leitora e a modelo, trazendo a realidade desta para o campo do possível, das relações próximas, fazendo com que as leitoras "comprem" (tanto no sentido de adquirir a revista quanto no que diz respeito à aceitação do estereótipo de mulher ideal defendido por ela) a mulher vendida pela revista.

Essa estratégia pode ser compreendida como um intercâmbio na posição discursiva ocupada pelas modelos, assim a revista faz um movimento de retirá-las do lugar do inalcançável ou impossível que ocupam no imaginário social e as desloca para a posição discursiva de mulher comum, aquela que é como a leitora, porém tem um segredo capaz de fazer com que essa seja capaz de atingir o corpo e status que elas possuem. Observa-se, então, a necessidade do movimento na posição discursiva (lugar que ocupam nos discursos construído pelo imaginário social e cultural) das modelos para que a revista seja capaz de atingir o lugar (lugar empírico em que estão situadas as leitoras) ocupado pelas mulheres que buscam o conteúdo por ela divulgado. ${ }^{18}$

A escolha do termo "boa", empregado já no título da revista, revela a ideia de que a mulher de corpo magro não é apenas mais uma das possibilidades estéticas e identitárias passíveis de serem assumidas por uma mulher, mas aquela que é correta, adequada e qualificada, aquela que a "boa" mulher deve assumir. Esse argumento é possível quando refletimos sobre o Esquecimento

d Estes trechos foram retirados, respectivamente, das revistas Boa Forma dos meses de janeiro e maio de 2015. 
número 2, que cria a ilusão de que a única forma de estruturar um discurso é pelo uso das exatas palavras que foram empregadas nele, quando na verdade as palavras utilizadas refletem as filiações ideológicas adotadas por aqueles que o produzem. ${ }^{15,18}$

Outra questão relevante demonstrada nas capas da revista refere-se à redução da mulher ao corpo que ela possui e, de forma ainda mais específica, à estética de seu abdômen/barriga ("Trinque a barriga com nossa série de pranchas" / "Barriga TOP" / "Cintura fina em um pulo"

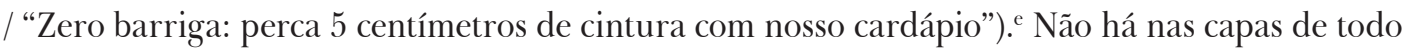
o ano de 2015 notícias ou matérias que remetam a outros aspectos da vida da mulher além da busca pelo corpo que alcance a "boa forma", mas as modelos escolhidas para ilustrá-las permeiam o imaginário popular carregadas de outros sentidos, como o sucesso, a competência, o status e a realização pessoal/profissional.

Nesse sentido, pode-se dizer que a revista faz o exercício de instigar (de modo inconsciente), em seu discurso, a associação entre a "boa" forma e o bem-estar/realização/sucesso em todos os outros campos de existência feminina, como se o corpo ideal fosse o caminho de acesso para todos eles e, mais que isso, como se toda e qualquer mulher, ao apropriar-se do "segredo" das modelos, fosse capaz de atingir a plenitude de sua existência - plenitude esta socialmente construída e reafirmada pela revista em sua veiculação. Há nesse movimento uma completa retirada da história das mulheres, tanto no sentido individual (na desconsideração de suas particularidades subjetivas, biológicas e contextuais), quanto no social, tendo em vista que a sociedade brasileira ainda é marcada pela dominação masculina. Isso acentua a desigualdade entre os gêneros e, consequentemente, faz com que a busca pela realização feminina seja atravancada por obstáculos que não estão relacionados unicamente a seus corpos e permeiam tanto os ambientes públicos quanto os privados frequentados pelas mulheres. ${ }^{26,27}$

Por fim, é possível dizer que, segundo as capas analisadas, ser mulher e ter "boa forma” são construtos ideológicos, já que os sentidos produzidos pela revista são perpassados essencialmente pelos dois pilares da Ideologia: a naturalização dos modos de relação e a Meritocracia. ${ }^{17}$ Dessa forma, os corpos das mulheres (que é o que lhes resta, após a redução que sofrem quando estampadas na capa ou tendo acesso a ela) é esvaziado de sua história e particularidades, assim como aquilo que é bonito/bom, passando por um processo de naturalização como se não houvesse influência cultural e social na constituição dos corpos e nos conceitos de bonito/bom. Além da naturalização, há a Meritocracia, já que no processo de desconsideração das condições histórico-sociais apresentadas por cada leitora da revista, cria-se a ideia de que cada mulher é a única responsável por atingir a "boa" forma e, em seguida, toda realização pessoal e profissional que a acompanha.

e Estes trechos foram retirados, respectivamente, das revistas Boa Forma dos meses de março, abril, maio e setembro de 2015. 


\section{O corpo obeso, as dietas e a saúde}

Observando as capas da revista, pode-se notar o uso recorrente e sempre em destaque de termos como "detonar", "enxugar", "secar" e "derreter" (a gordura), que remetem a formas de "exterminar" a gordura corporal indesejada. O uso destes termos não é casual, se retomarmos o conceito de interdiscurso.

Segundo Orlandi, ${ }^{18}$ o interdiscurso diz respeito a algo que já foi dito e que causa efeito no que se está sendo dito. Em todo o discurso (dizer) está presente o interdiscurso (já-dito), já que o último é todo o conjunto de formulações feitas e já esquecidas que possibilitam o nosso dizer. Nesse sentido, a escolha desses termos remete ao que está na memória e no contexto sócio-histórico contemporâneo de rejeição ao corpo obeso, por estigmatizar a gordura e considerar o corpo magro como o padrão de beleza ideal e incontestável.

Pode-se afirmar que vivemos em uma sociedade lipofófica, onde crenças, atitudes, valores e estigmas negativos frente ao indivíduo com excesso de peso são comuns. ${ }^{28-31}$ Ter um corpo magro, em uma sociedade que abomina a gordura, acaba se tornando um símbolo de poder, uma vez que o tamanho corporal acaba por classificar e qualificar as pessoas em relação a sua moral e personalidade. ${ }^{32}$

Assim, todos os símbolos e valores historicamente construídos e relacionados ao indivíduo obeso e ao corpo gordo estão também significando no que está sendo dito nas capas da revista. A supervalorização do corpo magro como o único tipo de corpo aceitável para a sociedade atual transforma a gordura em um símbolo de falência moral. ${ }^{33}$ A gordura torna-se a grande inimiga do corpo e da saúde, daí a necessidade de "detoná-la". Sob essa perspectiva, mesmo que não explicitamente escrito ou exposto nas capas, todos esses significados estão presentes e auxiliam na produção dos sentidos.

O corpo desejável, cultural e historicamente construído, não reflete apenas o contexto social, mas também carrega consigo relações de poder. ${ }^{34} \mathrm{O}$ excesso de gordura no corpo se converte em uma marca social e moral indesejável que desqualifica os sujeitos devido à não adequação aos padrões de aparência atuais. ${ }^{33}$

Com o processo de medicalização do corpo e da dieta, as pessoas gordas têm sido cada vez mais estigmatizadas como transgressores das normas nutricionais, e mesmo que a obesidade esteja atrelada a diversas causas orgânicas, as pessoas gordas são consideradas pessoas que comem demais. ${ }^{34}$ Como exemplo adicional, podemos fazer uma alusão também a incontáveis brincadeiras, facilmente encontradas na internet, que associam o consumo de alimentos calóricos, como doces e frituras, ao termo "gordice". O uso deste termo evoca sentido de que o consumo desses tipos de alimentos, dessas "gordices", é uma característica inerente à pessoa obesa: alguém que come mal, 
que não cuida de sua alimentação, que não tem controle. O termo estigmatiza, ao mesmo tempo, o indivíduo obeso e determinados tipos de alimentos, considerados "inimigos da dieta".

A exaltação do corpo magro e das dietas como forma para conquistá-lo traz em si, ainda que de forma encoberta, a posição ideológica e a expressão de valores, crenças e simbolismos, construídos em dado contexto histórico da sociedade. Uma vez que a obesidade é um símbolo de transgressão de normas e uma doença a ser evitada, o "fazer dieta" simboliza controle e moralidade, ${ }^{34}$ pois as dietas são formas eficientes de "se ver livre dos quilos extras em pouco tempo", o que é algo culturalmente desejável. Nesse contexto, podemos inferir que as dietas são uma forma de exercício de controle sobre os corpos, para adequá-los ao padrão estético estabelecido. Não é sem motivos que a relação "quilos perdidos x tempo" ganha destaque em basicamente todas as capas analisadas. A promessa de perda de peso de forma rápida / imediata / quase instantânea ("Magra em 5 minutos" / "Perca até 3kg em 1 semana tomando sopa a noite" / "Dieta clean: menos 5kg em 21 dias" / "Glúten-free: menos 4kg em 15 dias"), ${ }^{f}$ sempre associada a alguma dieta "do momento", é recorrente nas capas analisadas.

Retomando o conceito de interdiscurso, destacamos também que o uso recorrente da palavra "dieta”, sempre destacado em letras grandes ou em cores contrastantes com o fundo, não é obra do acaso. Segundo Orlandi, ${ }^{18}$ ao falarmos, nos filiamos a uma rede de sentidos, e a forma como as palavras nos afetam, produzem sentido e significam em nós é determinada por nosso contexto sócio-histórico e por nossas experiências simbólicas e de mundo.Voltando nosso olhar para o processo de construção do significado da palavra "dieta" na sociedade contemporânea, destacamos que, historicamente, esta palavra é ligada aos sentidos de perda de peso/emagrecimento por meio da restrição/controle da alimentação, com vistas a "eliminar" a gordura do corpo, uma vez que a gordura, além de ser imoral, é vista, sobretudo nos países industrializados, como sinônimo de doença e de falência. ${ }^{32,35}$

O sentido de facilidade atrelado as dietas também faz parte do discurso das capas, como por exemplo, a "dieta flex: menos 4kg em 30 dias, basta reduzir a carne do cardápio” ou com o "cardápio fácil para detonar a gordura"." Este discurso nos remete à culpabilização do indivíduo obeso por sua condição: já que fazer dietas é vendido como algo tão simples e fácil, bastaria o indivíduo querer e ter força de vontade para conseguir. Nesse discurso, temos capilarizado o conceito da Meritrocacia, ${ }^{17}$ uma vez que considera o indivíduo obeso como único responsável por seu sucesso (e também por seu fracasso) com as dietas e com o emagrecimento, destacando-o de seu contexto social e histórico. A sociedade atribui ao indivíduo com excesso de peso toda a responsabilidade por sua condição, cabendo também a ele a sua solução. ${ }^{36-38}$

f Estes trechos foram retirados, respectivamente, das revistas Boa Forma dos meses de junho, julho, novembro e dezembro de 2015 . 
Tal discurso também apresenta uma visão bastante simplista do processo de perda de peso, como se ela dependesse apenas da relação calorias ingeridas x calorias gastas, reduzindo o comer a uma simples operação matemática. Esta visão medicalizada da nutrição, baseada em normas e recomendações de ingestão de nutrientes/calorias necessários ao bom funcionamento do corpo biológico, reduz a comida a um mero fornecedor de nutrientes, ignorando dimensões sociais, políticas, culturais, simbólicas e emocionais do alimento. ${ }^{39}$

O crescimento do conhecimento do papel da dieta na prevenção de doenças e promoção de saúde contribuiu para a medicalização do comer e da obesidade. A normatização da dieta, com o estabelecimento de regras para ensinar as pessoas como comer - ou seja, o que comer, quando comer, quanto comer, alimentos que devem ser restritos ou preferidos - fazem parte do discurso puramente biomédico da obesidade na sociedade contemporânea, ${ }^{32}$ do qual a mídia se apropria para produzir seu próprio discurso. Uma vez que reduzem o consumo alimentar à mera ingestão de nutrientes, essas dietas incorporam, além da dimensão restritiva, um elemento de desidentificação alimentar que propõe uma separação condicional da dimensão hedonista do ato de comer. ${ }^{40}$ Isso em nada contribui para as reais mudanças no comportamento alimentar e nos hábitos de vida inerentes ao processo de perda de peso que, ao contrário do que se prega nas capas da revista, é de difícil alcance e exige grandes esforços. Diante dessa complexidade, fica claro que lidar com mudanças e restrições na alimentação não pode ser tarefa fácil.

As restrições impostas pelas dietas repercutem de forma extremamente negativa no comportamento alimentar dos indivíduos, sendo um forte gatilho para o comer excessivo, para o craving ${ }^{\mathrm{h}}{ }^{41,42}$ especialmente para os alimentos que estão sendo restringidos, para o desenvolvimento de transtornos alimentares graves e até mesmo para o ganho de peso a médio e longo prazos, o que é exatamente o contrário ao que se almeja com a realização de dietas. ${ }^{43-47}$

O que não é explicitado é que as (falsas) promessas de dietas que irão "eliminar", "enxugar", "derreter" e "exterminar" os quilos (supostamente) extras em tão pouco tempo ocultam a ineficácia, inexequibilidade e os prejuízos de se fazer dietas restritivas para emagrecer. Pode-se inferir que as dietas propostas são restritivas amparadas no fato de que perdas de peso rápidas, como as que são propostas, envolvem necessariamente a adoção de restrições alimentares significativas, tanto da quantidade quanto da qualidade do que se come. Souza et al. ${ }^{48}$ avaliaram a adequação nutricional de dietas para perda de peso em revistas não científicas e encontraram que $64 \%$ delas tinham valor calórico menor ou igual a 1.200kcal (média de 1.183,3 $\pm 428,0 \mathrm{kcal}$ ), e que 53,6\% e 45,7\% apresentavam quantidades insuficientes de carboidratos e lipídios, respectivamente, e 78,1\% quantidades excessivas de proteína.

h O craving é definido como o desejo intenso por alguma substância, com aumento dos esforços e da motivação na busca e obtenção dessa substância. ${ }^{40,41} \mathrm{O}$ termo tem sido também utilizado para se referir ao desejo de buscar e consumir determinados alimentos, ou dificuldade de resistir a eles. 
Metas de perda de peso irreais e ideais de beleza impossíveis de serem alcançados reforçam a insatisfação corporal e a relação deturpada com o comer, em nada contribuindo para a saúde física e mental do indivíduo. Ao contrário, pode-se arriscar dizer que dietas em geral, como as propostas nas capas, são planejadas para não funcionar, assim como os ideais de corpo são feitos para não serem atingidos. De outra forma não seria possível renovar, a cada edição, as promessas de perda de peso rápido com a mais nova dieta da moda.

\section{Considerações finais}

Após compreender que o corpo não pode ser reduzido a sua dimensão física, mas que há uma série de outras dimensões que o perpassam e o constituem simultaneamente - como a social, a histórica, a cultural, a econômica, entre outras -, torna-se de extrema importância compreender quais sentidos têm circunscrito os sujeitos e de que forma eles sofrem influência e controle por meio dos mecanismos de poder que se disseminam nos discursos veiculados, por exemplo, nas/ pelas revistas que compõem este estudo.

Foi possível perceber que existem, para além das informações expostas às claras na composição das capas, não ditos que ressoam e produzem sentido quando contextualizados histórica, social e culturalmente. Ou seja, não há nas capas apenas sugestões de dietas alimentares e proposição de exercícios físicos capazes de operar perdas de peso milagrosas, mas a exposição de um corpo e de uma mulher ideal (ou ideal de mulher). Nesse sentido, a revista perpetua um modelo a ser seguido, que desconsidera os contextos diferenciados dos quais cada leitora faz parte, fazendo com que as proposições se cristalizem por fortes ferramentas ideológicas de apagamento histórico-social dos sujeitos que acessam a revista, como a meritocracia e a naturalização daquilo que é bom/bonito como verdades, e não reflexos culturais.

Também pôde-se perceber que o corpo magro, que atende às expectativas do belo socialmente instituído, é tratado como aparato indispensável à realização pessoal e profissional, fazendo associação direta da adequação aos padrões de beleza ao bem-estar e sucesso nas mais variadas dimensões da existência da mulher. Dessa forma, o modelo do feminino defendido pela revista exige que a mulher seja capaz de realizar-se com plenitude em todos os âmbitos pelos quais ela transita, o que representa uma desconsideração das dificuldades enfrentadas pela mulher nas diversas posições sociais que ocupa, frutos de uma sociedade com fortes traços patriarcais e demarcada por uma dominação ainda presente do masculino sobre o feminino.

Por fim, é possível dizer que a defesa do corpo magro como padrão pauta-se significativamente no discurso biomédico que legitima a magreza como ideal de corpo. Ou seja, há uma ligação socialmente construída entre o corpo magro e o corpo saudável, que é constantemente reafirmada por discursos carregados de "verdades" naturalizadas e culturalmente instituídas. Essa associação 
do corpo magro ao saudável gera, consequentemente, uma ligação contrária do corpo gordo ao aspecto da doença que, atrelada à facilidade com a qual a busca pelo corpo ideal é tratada nas capas da revista, gera sentimento de culpa, transtornos alimentares e impacta diretamente na identidade, autoimagem e modos de se relacionar dos sujeitos em sociedade.

Diante deste cenário, parece imprescindível aprofundarmos as reflexões sobre as visões simplistas que dão o tom da concepção de corpo ideal e de saúde que perpassam o ser mulher na contemporaneidade, que carregam consigo a ilusão de que existe alguma "receita" mágica, universal e que está ao alcance de todos. Aos profissionais, sobretudo da área da saúde, cabe especial atenção em abarcar e incorporar em suas condutas informações pertinentes às pluralidades e singularidades dos sujeitos, a fim de trabalhar em uma perspectiva de saúde física e mental.

\section{Referências}

1. Bóris GDJB, Cesídio MH. Mulher, corpo e subjetividade: uma análise desde o patriarcado à contemporaneidade. Revista Mal-Estar e Subjetividade 2007; 7(2):451-478.

2. Heinzelmann FL, Romani PF, Lessa AS, Silva MSS, Strey MN. A tirania da moda sobre o corpo: submissão versus subversão feminina. Revista Subjetividades 2014; 14(2):297-305.

3. Miguel RBP, Toneli MJ. De "moça prendada" a "menina superpoderosa”: análise das seções de cartas de leitoras da revista Capricho (1954-2004). História Unisinos 2008; 12(2):168-179.

4. Zorzan FS, Chagas ATS. Espelho, espelho meu, existe alguém mais bela do que eu? Uma reflexão sobre o valor do corpo na atualidade e a construção da subjetividade feminina. Barbarói 2001; (34):161-187.

5. Gracia-Arnaiz M. Fat bodies and thin bodies: cultural, biomedical and market discourses on obesity. Appetite 2010; 55(2):219-225.

6. Severiano MFV, Rêgo MO, Montefusco EVR. O corpo idealizado de consumo: paradoxos da hipermodernidade. Revista Mal-Estar e Subjetividade 2010; 10(1):137-165.

7. Dantas JB. Um ensaio sobre o culto ao corpo na contemporaneidade. Estudos e Pesquisas em Psicologia 2011; 11(3):898-912.

8. Rodrigues AA, Caniato AMP. "Corpo-mercadoria”, sob controle e punição: prenúncios de uma subjetividade aniquilada? Revista Mal-Estar e Subjetividade 2009; 9(2):647-687.

9. Goldenberg M. Gênero e corpo na cultura brasileira. Psicologia Clínica 2005; 17(2):65-82.

10. Camargo BV, Goetz ER, Bousfield ABS, Justo AM. Representações sociais do corpo: estética e saúde. Temas em Psicologia 2001; 19(1):257-268.

11. Túlio R. Padrões e estereótipos midiáticos na formação de ideais estéticos em adolescentes do sexo feminino. Revista Àrtemis 2014; 18(1):147-159.

12. Goldenberg M. Afinal, o que quer a mulher brasileira? Psicologia Clínica 2011; 23(1):47-64. 
13. Santos MA, Díez-Garcia RW, Santos ML. A sujeição aos padrões corporais culturalmente construídos em mulheres de baixa renda. Demetra 2015; 10(4):761-774.

14. Pêcheux M. Análise Automática do Discurso (AAD-69). In: Gadet F; Hak T, organizadores. Por uma análise automática do discurso: uma introdução à obra de Michel Pêcheux Campinas, SP: Editora Unicamp; 1997. p. 61-105.

15. Caregnato RCA, Mutt R. Pesquisa qualitativa: análise de discurso versus análise de conteúdo. Texto Contexto Enfermagem 2006; 15(4):679-684.

16. Pires VL, Sobral A. Implicação do estatuto ontológico do sujeito na teoria discursiva do círculo Bakhtin, Medvedev, Voloshínov. Bakhtiniana 2013; 8(1):205-219.

17. Chauí M. O que é Ideologia. São Paulo: Brasiliense; 2012. 47 p.

18. Orlandi EP. Análise do discurso: princípios e procedimentos. Campinas: Pontes; 2013. 100 p.

19. Almeida TL. "Uma beleza que vem da tristeza de se saber mulher": representações sociais do corpo feminino [dissertação]. Brasília: Universidade de Brasília; 2009. 183 p.

20. Ramos DP. Pesquisas de usos do tempo: um instrumento para aferir as desigualdades de gênero. Estudos Feministas 2009; 17(3):861-870.

21. Vilhena J, Medeiros S, Novaes JV. A violência da imagem: estética, feminino e contemporaneidade. Revista Mal-Estar e Subjetividade 2005; 5(1):109-144.

22. Siqueira DCO, Faria AA. Corpo, saúde e beleza: representações sociais nas revistas femininas. Comunicação, Mídia e Consumo 2007; 4(9):171-188.

23. Lima AF, Batista KA, Lara Junior N. A ideologia do corpo feminino perfeito: questões com o real. Psicologia em Estudo 2013; 18(1):49-59.

24. Lane STM, Codo W. Psicologia social: o homem em movimento. São Paulo: Brasiliense; 1984. 220 p.

25. Martins SO. Análise do discurso. Revista Científica da AJES [Internet] 2011; 2(3). [acesso em: 20 fev. 2016]. Disponível em: http://www.revista.ajes.edu.br/arquivos/artigo_20110220121606.pdf.

26. Oliveira EPT. Mulher em conflito com a lei: a ressignificação de identidades de gênero em um contexto prisional. RBLA 2009; 9(2):391-414.

27. Ribeiro JSB. Brincadeiras de meninas e de meninos: socialização, sexualidade e gênero entre crianças e a construção social das diferenças. Cadernos Pagu 2006; 26(1):145-168.

28. Cori G, Petty ML, Alvarenga MS. Atitudes de nutricionistas em relação a indivíduos obesos: um estudo exploratório. Ciênc. Saúde Coletiva 2015; 20:565-576.

29. Teixeira F, Pais-Ribeiro JL, Maia A. Uns desistem, outros insistem: semelhanças e diferenças no discurso de profissionais de saúde face à obesidade. Rev. Port. Saúde Pública 2015; 33(2):137-147.

30. Teixeira FV, Pais-Ribeiro JL, Maia AC. Beliefs and practices of healthcare providers regarding obesity: a systematic review. Rev. Assoc. Med. Bras. 2012; 58:254-262.

31. Campbell K, Crawford D. Management of obesity: attitudes and practices of Australian dietitians. Int. J. Obes. Relat. Metab. Disord. 2000; 24:701-710. 
32. Gracia-Arnaiz M. Comer bien, comer mal: la medicalización del comportamiento alimentar. Salud Pública de México 2007; 49(3):236-2

33. Mattos RS, Luz MT. Sobrevivendo ao estigma da gordura: um estudo socioantropológico sobre obesidade. Physis 2009; 19(2):489-507.

34. Gracia-Arnaiz M. Thou shalt not get fat: medical representations and self-images of obesity in a mediterranean society. Health 2013; 5(7):1180-1189.

35. Neves AS, Mendonça ALO. Alterações na identidade social do obeso: do estigma ao fat pride. Demetra 2014; 9(3):619-631.

36. Sonntag U, Brink A, Renneberg B, Braun V, Heintze C. GPs' attitudes, objectives and barriers in counselling for obesity: a qualitative study. Eur. J. Gen. Pract. 2012; 18:9-14.

37. Jallinoja P, Absetz P, Kuronen R, Nissinem A, Talja M, Uutela A, et al. The dilemma of patient responsibility for lifestyle change: perceptions among primary care physicians and nurses. Scand. J. Prim. Health Care 2007; 25:244-249.

38. Ogden J, Bandara I, Cohen H, Farmer D, Hardie J, Minas H, et al. General practitioners' and patients' models of obesity: whose problem is it? Patient Educ. Couns. 2001; 44:227-233.

39. Villagelim ASB, Prado SD, Freitas RF, Carvalho MCVS, Cruz CO, Klotz J et al. A vida não pode ser feita só de sonhos: reflexões sobre publicidade e alimentação saudável. Ciênc. Saúde Coletiva 2012; 17(3):681-686.

40. Azevedo E. Liberem a dieta. Demetra 2015; 10(3):717-727.

41. Yanovski S. Sugar and fat: cravings and aversions. J. Nutr. 2003; 133(3):835S-837S.

42. Avena NM, Rada P, Hoebel BG. Evidence for sugar addiction: behavioral and neurochemical effects of intermittent, excessive sugar intake. Neurosci. Biobehav. Rev. 2008; 32(1):20-39.

43. Polivy J. Psychological consequences of food restriction. J. Am. Diet Assoc. 1996; 96:589-592.

44. Polivy J, Herman CP. An evolutionary perspective on dieting. Appetite 2007; 47:30-35.

45. Herman CP, Mack D. Restrained and unrestrained eating. J. Pers. 1975; 43(4):647-60.

46. Polivy J, Herman CP. Dieting and binging: a causal analysis. Am. Psychol. 1985; 40(2):193.

47. Polivy J, Herman CP. Distress and eating: why do dieters overeat? Int. J. Eat. Disord. 1999; 26(2):153-164.

48. Souza MG, Andrade IEL, Ramalho AA. Adequação nutricional de dietas para perda de peso em revistas não científicas brasileiras. Demetra 2015; 10(4):947-961.

Recebido: 11/4/2016

Revisado: 27/7/2016

Aceito: 16/8/2016 